\title{
A STRUCTURAL EQUATION MODEL INVESTIGATING THE IMPACT OF TERTIARY STUDENTS' ATTITUDES TOWARD STATISTICS, PERCEIVED COMPETENCE AT MATHEMATICS, AND ENGAGEMENT ON STATISTICS PERFORMANCE
}

\author{
KONSTANTINOS LAVIDAS \\ University of Patras, Greece \\ Lavidas@upatras.gr \\ TASOS BARKATSAS \\ RMIT University, Australia \\ tasos.barkatsas@rmit.edu.au \\ DIONISIOS MANESIS \\ National and Kapodistrian University of Athens, Greece \\ manesis_d@yahoo.com \\ VASILIOS GIALAMAS \\ National and Kapodistrian University of Athens, Greece \\ bgialamas@ecd.uoa.gr
}

\begin{abstract}
Research in the field of statistics teaching has gained momentum, with numerous studies reporting that attitudes towards statistics are related to student performance in a statistics course. The aim of this study was to explore the effects of students' attitudes toward statistics, students' perceived competence at mathematics, and students' engagement in the learning process on their overall performance in a tertiary statistics course. The Survey of Attitudes Toward Statistics (SATS-28) was administered to 170 tertiary Early Childhood Education students in a large university in Greece. A Structural Equation Model was generated, and a confirmatory factor analysis was performed resulting in a three-component structure being accepted. Path analysis revealed direct links between perceived competence at mathematics and the three attitudes components, as well as a direct effect of perceived competence at mathematics on students' performance in the statistics course. Engagement in the learning process also had a direct impact on students' performance.
\end{abstract}

Keywords: Statistics education research; Academic performance; Engagement in the learning process

\section{INTRODUCTION}

Enrollment in a statistics course is compulsory for students in Education undergraduate and postgraduate programs in Greek universities. The course consists of an introduction to the basic concepts of descriptive and inferential statistics. The objective of the course is to prepare students for specific educational and applied statistics topics and to address real-life problems that require the use of statistics beyond their studies effectively (Ben-Zvi \& Makar, 2016). Knowledge of statistics can help students analyze and interpret real-life data with competencies such as the use of appropriate statistical techniques, the capacity to answer research questions, and the capacity to interpret research results and report them in various academic settings and professional journals (Bechrakis et al., 2011).

Research in the field of teaching tertiary statistics has gained momentum with numerous studies reporting that attitudes toward statistics have a relationship with students' performance in a Statistics

Statistics Education Research Journal, 19(2), 27-41, http://iase-web.org/Publications.php?p=SERJ

(C) International Association for Statistical Education (IASE/ISI), June, 2020 
course (Emmioğlu \& Çapa-Aydın, 2012; Chiesi \& Primi, 2010; Coetzee \& van der Merwe, 2010; Nasser, 2004; Ramirez et al., 2012). Some of these studies highlight the role that students' background in mathematics and the associated student performance in those courses may have on students' attitudes towards statistics (Chiesi \& Primi, 2010; Nasser, 2004; Sesé et al., 2015; Stanisavljevic et al., 2014). The level of students' engagement in the educational process has also been recognized as a performance predictive factor in various tertiary courses (Budé et al., 2007; Carini et.al, 2006; Reyes et al., 2012; Veiga et al., 2014). The role of engagement in tertiary statistics courses, however, has not been sufficiently investigated. In this paper, we will investigate the impact of those predictive factors on Greek tertiary education students' engagement and performance. This investigation will strengthen the existing research literature on the predictive value of attitudes toward statistics and on the importance of students' engagement on their overall performance in an introductory statistics course. Additionally, we will enrich the existing research literature on the factors that have an impact on tertiary students' engagement in statistics classes. The cultural dimension provides an additional contribution to the research literature. Greek tertiary students are culturally different from the cohorts of previously published studies. Additionally, Bechrakis et al. (2011) have argued that a three-factor model could offer an alternative to the four-factor model, which constitutes a significant contribution to research.

\subsection{BACKGROUND}

One of the factors predictive of students' performance in statistics is their attitudes toward statistics (Emmioğlu \& Çapa-Aydın, 2012; Gal \& Ginsburg, 2017; Kiekkas et al., 2015; Ramirez et al., 2012; Sesé et al., 2015; Stanisavljevic et al., 2014). Students' attitude toward statistics are considered a multidimensional construct (Emmioğlu, \& Çapa-Aydın, 2012; Ramirez et al., 2012; Schau, 2003; Schau et al., 1995) and demonstrate students' predisposition to be positively or negatively inclined toward statistics (Gal \& Ginsburg, 2017). According to Schau (2003), the four components of attitudes toward statistics are Affect (students' feelings concerning statistics), Cognitive Competence (students' attitudes about their intellectual knowledge and skills when applied to statistics), Value (students' attitudes about the usefulness, relevance, and worth of statistics in personal and professional life), and Difficulty (students' attitudes about the difficulty of statistics as a subject). Students' unfavorable attitudes toward statistics and mathematics are related to their poor performance (Bechrakis et al., 2011; Nasser, 2004). In fact, due to these experiences, students tend to remember the difficulty of the particular lesson rather than its usefulness and they consider it an obstacle to obtaining their degree (Nasser, 2004).

One of the outcomes of a meta-analysis of students' attitudes toward statistics studies incorporating a large sample of participants from different countries, with the overwhelming majority of them using SATS-28, demonstrated that attitudes toward statistics are important in explaining the level of performance in a statistics course (Emmioğlu \& Çapa-Aydın, 2012). According to Emmioğlu and ÇapaAydın (2012), the studies conducted up to and including 2011 found small to moderate correlations between the four attitudes components and performance identified by Schau (2003). Moderate correlations between Statistics Performance and the SATS component Affect (95\% CI: 0.28 to 0.32) and the between Statistics Performance and Cognitive Competence in statistics (95\% CI: 0.28 to 0.32) have also been reported. Low correlations between statistics performance and students' valuing of statistics (95\% CI: 0.19 to 0.23$)$ and students' perceptions about the Difficulty of statistics $(95 \%$ CI: 0.17 to 0.22 ) were also reported. In the case of Difficulty of statistics, the researchers reported that the participants who thought statistics was easier were high statistics achievers.

Other studies (Chiesi \& Primi, 2010; Coetzee \& van der Merwe, 2010; Nasser, 2004; Sesé et al., 2015; Stanisavljevic et al., 2014) also reported the effect of students' mathematics background both on the attitudes toward statistics and on their performance in the statistics course. Sesé et al. (2015) described that mathematics background was identified as a predictive factor of students' attitudes toward statistics and of students' performance in statistics. The authors argued that there is a direct positive effect on students' attitudes toward statistics and an indirect positive effect, via their attitudes, on performance. In the same study, the dimension of the mathematics background that the researchers defined as Self-perceived Mathematics Competence appeared to have positive correlations with the four attitudes components. These correlations were moderate for the Affect and the Cognitive Competence components and weak for the Value and Difficulty components. According to Chiesi and Primi (2010), mathematics background appeared to have an indirect positive effect on attitudes toward statistics and 
on statistics performance via the variable mathematical competence. Similarly, Stanisavljevic et al. (2014) and Coetzee and van der Merwe (2010) reported that the perceived competence in mathematics was positively and moderately correlated to the Affect and Cognitive Competence components, and weakly associated with the Value and Difficulty components of the SATS scale.

Fredricks et al. (2004) assumed that school engagement is malleable, responsive to contextual features, and amenable to environmental change. They claimed that research literature considers engagement as a multidimensional concept or even as a "meta" construct. They proposed the following three dimensions: Behavioural Engagement, which draws on student participation, Emotional Engagement, encompassing both positive and negative reactions to staff and the school in general, and Cognitive Engagement, which draws on the principle of students making an investment in learning (p. $60)$.

Attendance is not compulsory in Greek universities, so the researchers decided to investigate behavioral engagement as it has been hypothesized to correlate with the successful completion of the introductory statistics course. It has been reported that behaviorally engaged learners attend classes, are engaged in the learning process, and are interested in their learning (Reyes et al., 2012). It has also been argued that students who are engaged in the educational process are more likely to achieve their academic goals (Budé et al., 2007; Carini et al., 2006; Reyes et al., 2012), and that there is a positive correlation between the degree of students' engagement in the learning process and their performance in various courses. As far as statistics courses are concerned, very few studies have reported findings on the effects of engagement on performance. Budé et al. (2007) reported that Health Science students' behavioral engagement was a predictive factor in statistics performance, which appeared to be influenced by the Affect attitudes component. The researchers reported a weak positive effect of behavioral engagement on performance, as well as a weak positive effect of the Affect statistics attitudes component on the self-reported study of behavioral engagement. Additionally, Stanisavljevic et al. (2014) reported a weak correlation between perceived competence at mathematics and engagement.

From the three predictive factors that we have discussed in this article, only the Attitudes Toward Statistics factor appears to have been captured consistently by most studies. Mathematics Background has been measured either as mathematics ability or as perceived competence. Furthermore, a small number of studies conducted on the role of engagement in university statistics courses considered engagement as either effort or persistence. Our objective is to expand the existing research literature on the predictive nature of attitudes toward statistics, engagement, and mathematics background.

In this article, we present how students' perceived competence at mathematics, their attitudes towards statistics, and their engagement in the educational process predict the fluctuation of students' final performance in statistics. Structural equation modelling (SEM) is used as an approach to test and model the above predictors of statistical performance. This research involved 170 students in their third year of studies from the Department of Early Childhood Education at the University of Patras. The population is predominantly female and between the ages of 18-22 so gender and age are not included in our models.

\subsection{THE STRUCTURAL MODEL}

The variables that we have used in this research are the performance in statistics (Statistics final grade), the four components of attitudes toward statistics (Value, Affect, Cognitive Competence and Difficulty), the students' perceived competence at mathematics and the students' engagement in the educational process.

The model that we developed (Figure 1) was based on the literature reviewed in this article. In this model, there is a direct positive effect of Self-perceived Mathematics Competence on Statistics Final Grade (Emmioğlu \& Çapa-Aydın, 2012; Ramirez et al., 2012; Sesé et al., 2015; Stanisavljevic et al., 2014). Additionally, there is a direct positive effect of the affect component of SATS on engagement (Budé et al., 2007). The positive affect of Self-perceived Mathematics Competence: a) on each of the four SATS components is also shown in Figure 1 (Coetzee \& van der Merwe, 2010; Chiesi \& Primi, 2010; Sesé et al., 2015; Stanisavljevic et al., 2014); b) Engagement (Stanisavljevic et al., 2014); and c) Statistics Final grade (Chiesi \& Primi, 2010; Nasser, 2004; Sesé et al., 2015; Stanisavljevic et al., 2014). Finally, there is a direct positive effect of the Engagement on Statistics Final Grade (Budé et al., 2007; Stanisavljevic et al., 2014). 


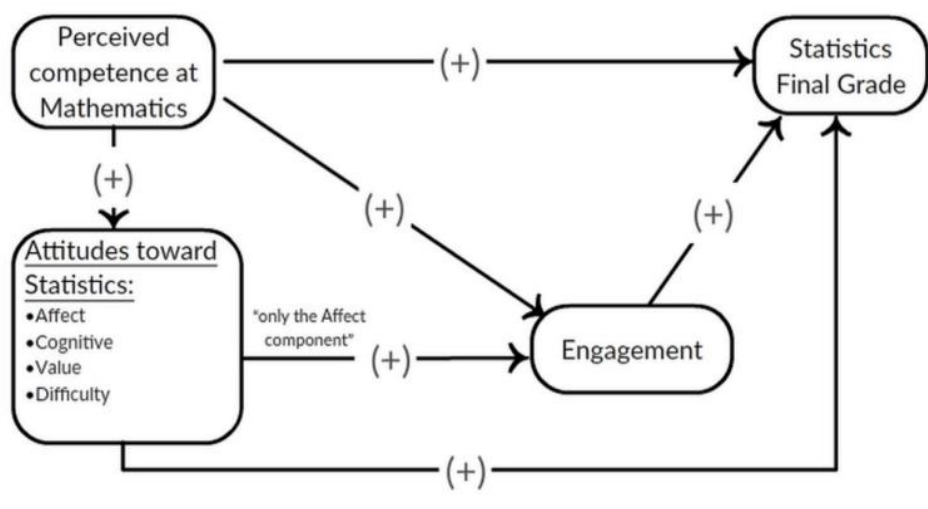

Note: (+) indicates a positive effect

Figure 1. The structural model for Statistics Performance

The factorial structure of the attitudes toward statistics scale will be investigated before the structural model is confirmed. The authors decided to test the reliability and the structural validity of scores from the scale because this study's student cohort is culturally different from the cohorts of previous studies. Additionally, the four-component factorial structure has been questioned in previous studies (Bechrakis et al., 2011; Nolan et al., 2012; Vanhoof et al., 2011). For example, in a previous study with a sample from the same cultural milieu, Bechrakis et al. (2011) reported that the cognitive competence and affect components could be merged into one component.

\subsection{AIMS OF THE STUDY}

The aims of the research were: a) to investigate the factorial structure of students' attitudes toward statistics; and b) to fit the structural model and to discuss results according to previous literature findings.

\section{RESEARCH METHODS}

\subsection{RESEARCH PROCEDURE}

Data collection took place through the distribution of the questionnaires during two academic years, 2016-2017 and 2017-2018, from October 2016 until January 2018. The lecturer/tutor (the first author) taught the same compulsory course, "Introduction to Statistics," from October through February with a total of 13 three-hour lectures during each academic year. Each year, data were collected in three stages. For this study, a seven-digit code was used by each participant at all three stages. All students enrolled in the introductory statistics course were asked to participate voluntarily in the research. They were presented with the research aims and each participant was assured that their data would be used only for research purposes. In order to avoid duplicate codes, students were asked to use the last seven digits of their mobile phone numbers. In the first stage, before the lectures began (October 2016 and October 2018), the students completed the SATS-28 and perceived competence at mathematics scales online. In the second stage, by the end of the lecture period (January 2016 and January 2018), the same students completed a scale regarding their engagement in the educational process online. The third stage was made up of the written final examination and the assessment of students' performance in the statistics course.

\subsection{RESEARCH INSTRUMENTS}

The questionnaire administered to the students in the first stage consisted of two sections of thirtythree closed questions. In the first section, there were questions about gender, age, the seven-digit code, and two other questions (based on a 7-point Likert type scale, $1=$ Not good at all to $7=$ Excellent). The 
two other questions were: a) how good were you in high school mathematics and b) how good are you in mathematics?

The second section consisted of twenty-eight statements of the scale of students' attitudes towards statistics. The Survey of Attitudes Toward Statistics was used to measure statistical attitudes (Schau et al., 1995), with 28 statements (SATS-28). The SATS-28 Greek version translated by Anastasiadou and Papadimitriou (2002) was used in this study. The SATS-28 is one of the latest and most widely used instruments for measuring attitudes (Emmioğlu \& Çapa-Aydın, 2012; Coetzee \& van der Merwe, 2010; Ramirez et al., 2012; Vanhoof et al., 2011). This scale takes into account the multidimensional structure of attitudes toward statistics and includes four subscales: a) Affect - 6 items: Students' feelings towards statistics - Example: 'I'm afraid of statistics"; b) Cognitive Competence - 6 items: Students' attitudes about their intellectual knowledge and their skills applied in statistics; for example, "I can learn statistics"; c) Value - 9 items: Students' attitudes towards usefulness, relativity, and value of statistics in the personal and professional life; for example, "I use statistics in everyday life"; and d) Difficulty 7 items: Students' attitudes towards the difficulty of statistics as a lesson; for example: "Most people need to learn a new way of thinking in order to learn/apply statistics." The scale can be applied to most if not all university departments offering statistics courses at any time of the course (Schau, 2003).

The students answered every question on a 7-point Likert type scale from 1 (I strongly disagree), 4 (I do not agree or disagree (neutral)), to 7 (I strongly agree). For the 19 items that have been written in negative form, responses are reversed before evaluation, so higher value responses mean more positive attitudes. Positive attitudes are self-explanatory for all except for Difficulty, as higher scores mean that students consider statistics to be easy, while lower scores mean they find it difficult. Students typically spend 10-15 minutes to complete this questionnaire (Schau, 2003). In terms of reliability, which refers to the internal consistency of the subscales compiling each scale, the Cronbach's alpha coefficient appeared to have high scores (>0.861) in the subscales Affect, Cognitive and Value. For the Difficulty subscale, the corresponding internal consistency is 0.671 , but this level is considered to be at least sufficient (Schau, 2003).

In the second stage, the instrument distributed to the students consisted of three questions. Namely, the seven-digit code and the following two items regarding students' engagement in the educational process: a) How regularly did you attend the lectures of the Statistics course? and b) How often did you take selective notes from the lectures of the Statistics course? A five-point scale ( $1=$ Almost/always, 2 $=$ Often, $3=$ Sometimes, $4=$ Rarely, $5=$ Never ) was used in this study. These two items were developed with the objective to investigate students' behavioral engagement in the educational process. Students' engagement in lectures and tutorials and simultaneous note taking was conjectured to behaviorally engage them in the education process (Budé et al., 2007; Carini et al., 2006; Reyes et al., 2012; Veiga et al., 2014).

The final assessment (stage three), was based on the marks of the final written test (prepared by the authors of the article) and consisted of two groups of items. It lasted for two hours. The first group consisted of ten multiple-choice statistical theory questions, with four alternative answers where only one answer was correct. The second group consisted of three computational data analysis exercises. These two groups of items were developed with the objective of having the same degree of difficulty, that is, equivalent mean performance and standard deviation (see Table 3). Each group of questions was marked with a maximum score of 5. Students' final performance was the sum of the two marks obtained in each of the two groups of questions. Note that the marking scale used in Greek Universities is 1 (extremely low) to 10 (excellent/outstanding).

All instruments used showed satisfactory psychometric properties, and the details are discussed in Section 3.

\subsection{DATA COLLECTION AND SAMPLE}

The introduction to statistics is a mandatory course conducted in one semester from October to February. In each academic year, approximately 240 pre-service student teachers are enrolled in the third year of Early Childhood Education Of the approximately 480 students over the two years of the survey, 154 and 145 students from the academic years 2016-17 and 2017-18, respectively, participated in the first stage. In the second stage, there were 122 and 120 students respectively and in the third stage, the numbers were 91 and 131. One hundred and seventy students who completed the three 
questionnaires in all three stages of the survey and for whom we were able to match their answers based on their "seven-digit code" -63 students (37\%) participated in the survey during 2016-17 and 107 students (63\%) participated in 2017-18. All students were third year students aged 20 to 21. Only one student was male.

\subsection{ANALYSIS OF DATA}

The R Programming Language (Ihaka \& Gentleman, 1996) was used in data management, as well as various descriptive analyses. All model tests were conducted on the appropriate covariance matrices using the Structural Equation Modelling software AMOS 23 (Arbuckle, 2007). Bootstrap resampling and maximum likelihood estimation (5,000 bootstrap samples) were used to test the indirect effects presented in fitted models.

\section{RESULTS}

\subsection{DATA SCREENING AND PSYCHOMETRIC PROPERTIES OF INSTRUMENTS}

Initially, 19 negatively worded items of SATS-28 were reversed, so that for all items a higher score corresponded to a more positive attitude toward statistics (Schau et al., 1995). In regard to the difficulty subscale, the higher the score of the items, the less the difficulty. The scores of the engagement scale are reversed so that high scores would correspond to higher engagement with the educational process.

Observations were identified as outliers using a Chi-square probability threshold of 0.001 (Mahalanobis, 1936). Three cases were identified as multivariate outliers: one case from the 2016-17 sample and two cases from the 2017-18 sample. The decision was to exclude these cases from the samples used in the data analysis.

Confirmatory factor analysis was used to evaluate the initial structure (four-component with 28 items) of the SATS-28 instrument. As shown in Table 1, the four-component structure 1. Overall fit statistics suggest a non-acceptable fit according to the guidelines proposed by $\mathrm{Hu}$ and Bentler (1999) and Browne and Cudek (1993). Considering the modification indices with regard to the covariance of error terms in the same components, the new structure presents an acceptable fit (Table 1).

Table 1. Confirmatory factor analysis indices for four-component structure 1 and 2 of SATS-28

\begin{tabular}{lccccccc}
\hline & $\chi^{2}$ & Df & $\chi^{2} / \mathrm{df}$ & NFI & TLI & CFI & RMSEA \\
\hline $\begin{array}{l}\text { Four-component } \\
\text { structure 1 }\end{array}$ & 911.646 & 345 & 2.642 & 0.778 & 0.833 & 0.848 & 0.077 \\
$\begin{array}{l}\text { Four-component } \\
\text { structure 2 }\end{array}$ & 612.901 & 332 & 1.846 & 0.851 & 0.914 & 0.925 & 0.055 \\
\hline
\end{tabular}

Considering the link of error terms on each component (Schumacker \& Lomax, 2004) and the marginally acceptable fit of the four-components structure 2 as well as the small sample size $(n=167)$, we created nine parcels (Bandalos, 2002) from the 28 items. Within each component (Table 2),

Table 2. Parcels' construction for each component of SATS-28

\begin{tabular}{lcc}
\hline Components & Parcel & Items \\
\hline \multirow{2}{*}{ Affect } & P_A1 & $1,2,11$ \\
& P_A2 & $14,15,21$ \\
Cognitive Competence & P_C1 & $3,9,23$ \\
& P_C2 & $20,24,27$ \\
Difficulty & P_D1 & $4,6,18$ \\
& P_D2 & $17,22,26,28$ \\
Value & P_V1 & $5,7,10$ \\
& P_V2 & $8,12,16$ \\
& P_V3 & $13,19,25$ \\
\hline
\end{tabular}


following the guidelines of Schau et al. (1995), the parcels were balanced with respect to a) the number of positively and negatively worded items; and b) the size of parcel means, standard deviations and skewness (Schau et al., 1995; Vanhoof et al., 2011).

In Table 3, the descriptive statistics of all variables used in this study are shown. Univariate parcel distributions show a slight departure from normal distribution $(\mid$ skewness $\mid<0.67)$ and $\mid$ Kurtosis $\mid<0.88$; Bulmer, 1979) as well as multivariate normal distribution (Mardia's coefficient $=2.61$; Byrne, 2010; Mardia, 1970).

Table 3. Descriptive statistics of variables $(n=167)$

\begin{tabular}{lcccccc}
\hline Variables & Min & Max & Mean & SD & Skew & Kurtosis \\
\hline P_A1 & 1.0 & 7.0 & 4.02 & 1.27 & -.43 & .01 \\
P_A2 & 1.0 & 7.0 & 4.25 & 1.56 & -.18 & -.88 \\
P_C1 & 1.0 & 7.0 & 4.89 & 1.29 & -.67 & .28 \\
P_C2 & 1.0 & 7.0 & 4.20 & 1.36 & -.47 & -.32 \\
P_D1 & 1.3 & 5.7 & 3.65 & .81 & -.25 & .32 \\
P_D2 & 1.0 & 5.8 & 3.59 & .81 & -.21 & .47 \\
P_V1 & 1.7 & 7.0 & 5.17 & 1.06 & -.41 & -.05 \\
P_V2 & 1.7 & 7.0 & 5.13 & 1.05 & -.42 & .15 \\
P_V3 & 1.0 & 7.0 & 4.95 & 1.23 & -.63 & .20 \\
PerCM_1 & 1.0 & 7.0 & 3.94 & 1.66 & .06 & -.94 \\
PerCM_2 & 1.0 & 7.0 & 3.78 & 1.50 & .03 & -.80 \\
Engag_1 & 1.0 & 5.0 & 4.12 & 1.07 & -1.11 & .45 \\
Engag_2 & 1.0 & 5.0 & 4.11 & 1.09 & -1.10 & .34 \\
Stat_Mark_1 & .5 & 5.0 & 2.96 & 1.15 & -.22 & -.72 \\
Stat_Mark_2 & .0 & 5.0 & 2.84 & 1.43 & -.35 & -.85 \\
\hline Note: P_A1, P_A2, P_C1, P_C2, P_D1, P_D2, P_V1, P_V2, P_V3 are parcels. PerCM_1 and PerCM_2 are \\
two items of perceived competence at the mathematics scale. Engag_1, Engag_2 are two items of \\
engagement scale. Stat_Mark_1, Stat_Mark_2 are two items of Final Grade (performance in statistics).
\end{tabular}

The structure of the four-component scale (Table 4), using parcels, presented a satisfactory fit. The very high correlation ( $r=0.99)$ between Affect and Cognitive components (see Figure 2), however, indicates a lack of discriminant validity and suggest a three-component structure of the scale.

Table 4. Confirmatory factor analysis indices for 4- and 3-component structures of SATS-28 using parcels

\begin{tabular}{lcccccccc}
\hline & $\chi^{2}$ & df & $p$-value & NFI & TLI & CFI & RMSEA (pclose) & AIC \\
\hline Four-components structure & 26.8 & 21 & 0.175 & 0.976 & 0.991 & 0.995 & $0.041(.594)$ & 92.881 \\
Three-components structure & 29.6 & 24 & 0.197 & 0.974 & 0.992 & 0.995 & $0.038(.652)$ & 71.646 \\
\hline
\end{tabular}

The structure of the three-component scale, resulting from the merging the two components (Figure $2)$, is also satisfactory.

The three-component structure has a lower AIC than the four-component structure, indicating it is the preferred structure (Kline, 2015). The difference of 21.235 is large enough to indicate substantial support for the three-component structure (Burnham \& Anderson, 2004). It is worth noting that this structure has been reported in a similar sample from other researchers (Bechrakis et al., 2011).

Both the construct validity and the reliability of the three-component structure are satisfactory (Table 5). The construct validity of a scale can be judged by convergent and discriminant validity. All loadings exceed the criterion value 0.7 (Figure 2) and Average Variance Extracted (AVE) indicates a satisfactory convergent validity exceeding 0.5 for all components (Fornell \& Larcher, 1981; Hair et al., 2017). The discriminant validity was investigated by the Heterotrait-Monotrait Ratio (HTMT; Henseler 

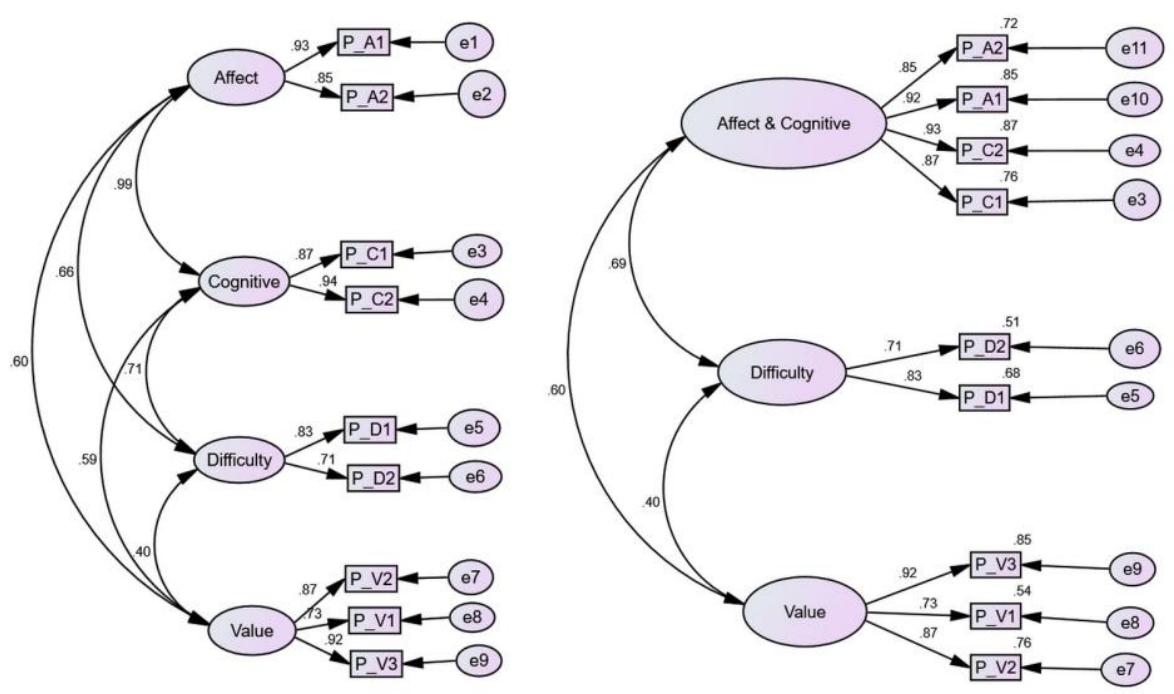

Figure 2. Structure of the four and three-component of SATS-28, with parcels

et al., 2015). Results indicate that none of the ratios exceed the criterion ratio 0.85 ; hence, the discriminant validity of the three components was acceptable.

Table 5. Reliability and construct validity of three-component structure of SATS-28

\begin{tabular}{|c|c|c|c|c|c|c|}
\hline \multirow[b]{2}{*}{ Components } & \multirow[b]{2}{*}{$\begin{array}{c}\text { Cronbach's } \\
\text { Alpha }\end{array}$} & \multirow[b]{2}{*}{$\mathrm{CR}$} & \multirow[b]{2}{*}{ AVE } & \multicolumn{3}{|c|}{ Heterotrait-Monotrait Ratio (HTMT) } \\
\hline & & & & $\begin{array}{c}\text { Affect_- } \\
\text { Cognitive }\end{array}$ & Difficulty & Value \\
\hline Affect-Cognitive & 0.937 & 0.942 & 0.802 & 1.00 & & \\
\hline Difficulty & 0.741 & 0.745 & 0.595 & 0.690 & 1.00 & \\
\hline Value & 0.880 & 0.883 & 0.717 & 0.582 & 0.386 & 1.00 \\
\hline
\end{tabular}

Reliability was assessed by the estimates of Cronbach's Alpha (Cronbach, 1951; Nunnally, 1978) and Composite Reliability (CR) values (Raykov, 1997). All three constructs of the three-component scale showed satisfactory reliability with coefficients greater than 0.7 (Table 5).

Finally, the reliability coefficients were satisfactory for the engagement (Cronbach's alpha $=0.772$ ) and the statistics final grade (Cronbach's alpha $=0.755$ ) scales and excellent for the perceived competence at mathematics scale (Cronbach's alpha $=0.939)$.

\subsection{MODEL OF STUDENTS' PERFORMANCE IN STATISTICS}

Initially, in the path analysis, the fit of the structural model was investigated. From this model, we derived the pruned model taking out the links corresponding to coefficients with values not different from zero. Coefficients path from attitudes toward statistics on the final grade $(p=0.254, p=0.265, p$ $=0.646)$ as well as the path from perceived competence at mathematics on engagement $(p=0.538)$ were removed. The pruned model (Figure 3), presents the final structural model among latent variables of students' attitudes toward Statistics, perceived competence at mathematics, engagement, and performance (latent variable: Final Grade) in statistics lesson, as well as the measurement model of the above-mentioned latent variables. The pruned model was accepted because of a negligible loss of fit $\left(\Delta \mathrm{x}^{2}=2.04, \mathrm{df}=4, p=0.067\right)$. The pruned model showed an acceptable fit as TLI (0.986) and CFI (0.989) indices were above the cutoff of 0.90 (Hu \& Bentler, 1999). Moreover, RMSEA $=0.038$ (CI: $0.000,0.061$ ) and SRMR $=0.042$ were below the .05 threshold (Browne \& Cudek, 1993). In this model, 
we present all standardized loadings ranging from 0.65 (for one item only) to 0.98 (Appendix, Table 7) and direct and indirect effects among variables (Appendix, Table 6).

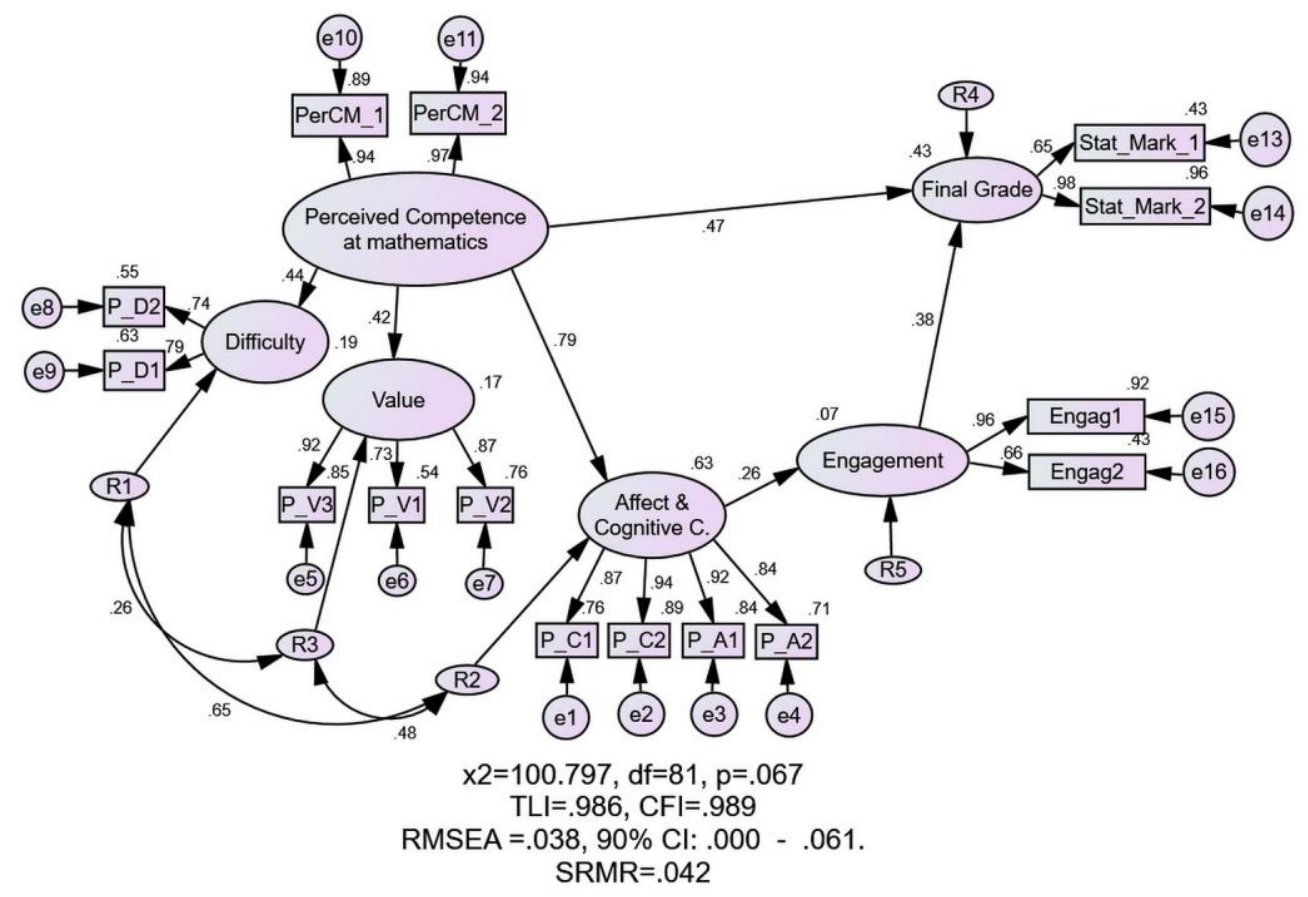

Figure 3. Pruned model: Prediction of the final grade in tertiary introductory statistics

The independent variables of the model accounted for a satisfactory amount of variance of students' final grade in statistics course $(43.2 \%)$. More specifically, there is a direct moderate effect $(0.467)$ of self-perceived mathematics competence and an indirect small effect (0.078) of self-perceived mathematics competence mediated by affect, cognitive competence, and engagement on the final grade (Bootstrap 95\% CI: 0.030, 0.131). Moreover, there is a moderate direct effect (0.376) of engagement on the final grade. We also notice an indirect effect of Affect and Cognitive Competence (0.099) on final grade (Bootstrap 95\% CI: 0.053, 0.235), mediated by the engagement. In regard to the impact of the self-perceived Mathematics Competence, we found direct moderate effects on Value (0.418), difficulty (0.437), and a large effect on affect and cognitive competence (0.791). Moreover, we notice an indirect effect of Self-perceived Mathematics Competence (0.208) on Engagement (Bootstrap 95\% CI: 0.167, 0.267), mediated by Affect and Cognitive Competence. Finally, there is a direct effect of Affect and Cognitive Competence (0.263) on Engagement.

\section{DISCUSSION AND CONCLUSION}

This paper has examined how students' perceived competence at mathematics, their attitudes towards statistics, and their engagement in the educational process predict the fluctuation of their final performance in statistics. A structural equation model (SEM) was used to test and model the predictors of statistical performance.

Initially, with regards to the factorial structure of the SATS-28 instrument, a three-component model was accepted, consisting of the value, affective-cognitive, and difficulty components of attitudes toward statistics. This finding indicates that for Greek Early Childhood Education students, affective and intellectual knowledge/skills when applied to statistics are so closely linked that they cannot be separated. Strong links between the affective and cognitive competence subscales $(r>0.9)$ were shown in other studies (Bechrakis et al., 2011; Nolan et al., 2012; Schau et al., 1995). A plausible interpretation for our findings is that Early Childhood Education students (mostly female) in Greece have strong (negative) feelings towards statistics that could contribute to low levels of cognitive competence (Bechrakis et al., 2011). 
Performance on statistics seems to be directly dependent on both students' perceived competence at mathematics and on their engagement in the educational process. The higher the perceived competence at mathematics (Coetzee \& van der Merwe 2010; Chiesi \& Primi, 2010; Sesé et al., 2015; Stanisavljevic et al., 2014) and the engagement (Budé et al., 2007; Carini et al., 2006; Reyes et al., 2012; Stanisavljevic et al., 2014), the higher the performance in statistics. Approximately $44 \%$ of the students' performance variability is explained by the predictor variables as they are described in the model.

From the three components of SATS-28, only the affective-cognitive component seems to explain students' performance in statistics moderately and indirectly. Students with more positive attitudes towards statistics demonstrate higher engagement and consequently higher performance in the statistics course. This result is aligned to the results reported by other researchers (Emmioğlu \& Çapa-Aydın, 2012; Kiekkas et al., 2015; Ramirez et al., 2012; Sesé et al., 2015; Stanisavljevic et al., 2014) who have reported that there were direct effects of all attitudes components on statistics performance. This differentiation is possibly due to the different models used by various researchers when they explain performance in statistics (Chiesi \& Primi, 2010; Sesé et al., 2015). It appears that behavioral engagement, which has not been investigated in previously reported studies, is the factor that primarily explains the impact of attitudes on performance. Another plausible explanation could be that similar to a number of previous studies, the sample consisted of psychology students.

Furthermore, students' perceived competence at mathematics appears to affect all components of their attitudes towards statistics (Coetzee \& van der Merwe, 2010; Chiesi \& Primi, 2010; Sesé et al., 2015; Stanisavljevic et al., 2014). Therefore, higher perceived competence at mathematics scores appears to be related to more positive attitudes toward statistics such as Value, Difficulty, and Affect and Cognitive Competence. In agreement with the current study's results, Stanisavljevic et al. (2014) and Coetzee and van der Merwe (2010) reported that the effect on the affect and cognitive competence components is strong, compared to the effect on the other two SATS-28 attitude components. Students' perceived competence at mathematics, however, does not fully explain the variance in but indirectly provides explanations via the affect and cognitive competence components (Stanisavljevic et al., 2014). We concur with Budé et al. (2007) who suggest that affect and cognitive competence components could offer a plausible explanation of increased levels of attendance in a tertiary statistics course.

Because performance in statistics is affected by the students' attitudes toward statistics, their selfperceived mathematics competence, and especially their engagement in the educational process, should be discussed extensively with the students so they become cognizant of the impact of these factors on their performance in tertiary statistics courses. In addition, it is very important that lecturers and instructors improve their efforts to facilitate students' mathematical skill set (Lavidas et al., 2017; Nasser, 2004) by providing opportunities for the students to realize that statistics is not a cognitively difficult academic subject (Ben-Zvi \& Makar, 2016). One of the objectives of an introductory statistics course is to include the fundamental learning concepts and techniques that will facilitate students' comprehension of more advanced statistical concepts (Schau, 2003). It is our contention that mathematics techniques have to be taught to strengthen students' statistical skills.

Moreover, we recommend creating emotionally and cognitively supportive learning environments where students will feel free to collaborate and conjecture, discover and trace their learning trajectory, free to experiment and take risks (Schau, 2003), by applying different statistical tools and methods and by generally feeling comfortable with the uncertainty of statistics. By utilizing this teaching approach, there is the potential to keep more students in the classroom, thus allowing students to become more engaged with the educational process (Lavidas et al., 2013; Schau, 2003).

The instruments that have been used in this study have limitations that have to be considered. The study of the factorial structure of SATS-28 via parcels is a limitation that has been discussed in the research literature (Vanhoof et al., 2011). We have, however, followed all the parceling rules (Bandalos, 2002) as well as the SATS-28 authors' instructions (Schau et al., 1995) in order to derive comparative results. Moreover, the three instruments used for students' engagement, perceived competence at mathematics as well as for the assessment of their performance, are based on few items and have not been used in previous surveys and thus may limit comparisons with published surveys using similar instruments. Additionally, the sample used does not consist of students in the same academic year but of students in two consecutive academic years, and a consequence, the survey was conducted in different teaching periods. 
Further research is required to test the validity and generalizability of our results and conclusions. It is important to investigate the various dimensions of engagement in the educational process and how these impact students' performance. Teaching approaches that facilitate student engagement should also be the focus of further investigations. Finally, future longitudinal studies involving students from various academic fields are required to further validate these findings.

\section{ACKNOWLEDGEMENTS}

We thank our students of the Department of Educational Sciences and Early Childhood Education of the University of Patras for their participation in the study. Their responses have informed our efforts to improve the quality of our statistics course. Also, we thank the anonymous reviewers for their very constructive and insightful comments.

\section{REFERENCES}

Anastasiadou, S., \& Papadimitriou J. (2002). [In Greek]. Applying data analysis methods in students' attitudes toward statistics teaching in order to determine university. Data Analysis Bulletin, 1(1), 65-74.

Arbuckle, J. (2007). Amos 16.0 users guide: SPSS. Amos Development Corporation.

Bandalos, D. L. (2002). The effects of item parceling on goodness-of-fit and parameter estimate bias in structural equation modeling. Structural Equation Modeling, 9(1), 78-102.

[Online: https://doi.org/10.1207/S15328007SEM0901_5]

Bechrakis, T., Gialamas, V., \& Barkatsas, A. N. (2011). Survey of Attitudes Toward Statistics (SATS): An investigation of its construct validity and its factor structure invariance by gender. International Journal of Theoretical Educational Practice, 1(1), 1-15.

Ben-Zvi, D., \& Makar, K. (2016). International perspectives on the teaching and learning of statistics. In D. Ben-Zvi \& K. Makar (Eds), The teaching and learning of statistics (pp. 1-10). Springer. [Online: https://doi.org/10.1007/978-3-319-23470-0]

Browne, M., \& Cudek, R. (1993). Alternative ways of assessing model fit. In K. Bollen \& J. Long (Eds.), Testing structural equation models (pp. 136-162). Newbury Park, CA: Sage Publications.

Budé, L., Van De Wiel, M. W., Imbos, T., Candel, M. J. J. M., Broers, N. J., \& Berger, M. P. (2007). Students' achievements in a statistics course in relation to motivational aspects and study. Statistics Education Research Journal, 6(1), 5-21.

Bulmer, M. G. (1979). Principles of statistics. Dover Publications.

Burnham, K. P., \& Anderson, D. R. (2004). Multimodel inference: Understanding AIC and BIC in model selection. Sociological Methods \& Research, 33(2), 261-304.

[Online: https://doi.org/10.1177/0049124104268644]

Byrne, B. M. (2010). Structural equation modeling with Amos: Basic concepts, applications, and programming $\left(2^{\text {nd }}\right.$ ed.). Routledge.

Carini, R. M., Kuh, G. D., \& Klein, S. P. (2006). Student engagement and student learning: Testing the linkages. Research in Higher Education, 47(1), 1-32.

[Online: https://doi.org/10.1007/s11162-005-8150-9]

Chiesi, F., \& Primi, C. (2010). Cognitive and non-cognitive factors related to students' statistics achievement. Statistics Education Research Journal, 9(1), 6-26.

[Online: https://www.stat.auckland.ac.nz/ iase/serj/SERJ9(1)_Chiesi_Primi.pdf]

Coetzee, S., \& Van der Merwe, P. (2010). Industrial psychology students' attitudes towards statistics. SA Journal of Industrial Psychology, 36(1), 1-8.

[Online: https://doi.org/10.4102/sajip.v36i1.843]

Cronbach, L. J. (1951). Coefficient alpha and the internal structure of tests. Psychometrika, 16(3), 297-334.

[Online: https://doi.org/10.1007/BF02310555]

Emmioğlu, E. S. M. A., \& Çapa -Aydin, Y. (2012). Attitudes and achievement in statistics: A metaanalysis study. Statistics Education Research Journal, 11(2), 95-102.

[Online: https://iase-web.org/documents/SERJ/SERJ11(2)_Emmioglu.pdf] 
Fornell, C., \& Larcker, D. F. (1981). Evaluating structural equation models with unobservable variables and measurement error. Journal of Marketing Research, 18(1), 39-50.

Fredricks, J. A., Blumenfeld, P. C., \& Paris, A. H. (2004). School engagement: Potential of the concept, state of the evidence. Review of Educational Research, 74(1), 59-109.

[Online: https://doi.org/10.3102/00346543074001059]

Gal, I., \& Ginsburg, L. (2017). The role of beliefs and attitudes in learning statistics: Towards an assessment framework. Journal of Statistics Education, 2(2). [Online: https://doi.org/10.1080/10691898.1994.11910471]

Hair, J. F., Hult, G. T. M., Ringle, C. M., \& Sarstedt, M. (2017). A primer on partial least squares structural equation modeling (PLS-SEM) ( $2^{\text {nd }}$ ed.). Sage Publications.

Henseler, J., Ringle, C. M., \& Sarstedt, M. (2015). A new criterion for assessing discriminant validity in variance-based structural equation modeling. Journal of the Academy of Marketing Science, 43, $115-135$.

[Online: https://doi.org/10.1007/s11747-014-0403-8]

Hu, L., \& Bentler, P. M. (1999). Cutoff criteria for fit indices in covariance structure analysis: Conventional criteria versus new alternatives. Structural Equation Modeling, 6(1), 1-55.

Ihaka, R., \& Gentleman, R. (1996). R: A language for data analysis and graphics. Journal of Computational and Graphical Statistics, 5(3), 299-314.

Kiekkas, P., Panagiotarou, A., Malja, A., Tahirai, D., Zykai, R., Bakalis, N., \& Stefanopoulos, N. (2015). Nursing students' attitudes toward statistics: Effect of a biostatistics course and association with examination performance. Nurse Education Today, 35(12), 1283-1288.

[Online: https://doi.org/10.1016/j.nedt.2015.07.005]

Kline, R. B. (2015). Principles and practice of structural equation modeling ( $3^{\text {rd }}$ ed.). Guilford Publications.

Lavidas, K., Komis, V., \& Gialamas, V. (2013). Spreadsheets as cognitive tools: A study of the impact of spreadsheets on problem solving of math story problems. Education and Information Technologies, 18(1), 113-129.

[Online: ]

Lavidas, K., Komis, V., \& Voulgari, I. (2017). Detecting errors during the construction of mathematical formulas in a spreadsheet environment: An empirical study involving novice users. SCIREA Journal of Education, 2(1), 1-17.

[Online: http://article.scirea.org/pdf/88015.pdf]

Mahalanobis, P. C. (1936). On the generalized distance in statistics. In Proceedings of the National Institute of Sciences of India, 2(1), 49-55.

Mardia, K. V. (1970). Measures of multivariate skewness and kurtosis with applications. Biometrika, 57(3), 519-530.

Nasser, F. M. (2004). Structural model of the effects of cognitive and affective factors on the achievement of Arabic-speaking pre-service teachers in introductory statistics. Journal of Statistics Education, 12(1), 1-28.

[Online: https://doi.org/10.1080/10691898.2004.11910717]

Nolan, M. M., Canada, C., \& Hecker, K. G. (2012). Surveys assessing students' attitudes toward statistics: A systematic review of validity and reliability. Statistics Education Research Journal, 11(2), 103-123.

[Online: https://iase-web.org/documents/SERJ/SERJ11(2)_Nolan.pdf]

Nunnally, J. C. (1978). Psychometric theory. McGraw-Hill.

Ramirez, C., Schau, C., \& Emmioğlu, E. (2012). The importance of attitudes in statistics education. Statistics Education Research Journal, 11(2), 57-71.

[Online: https://iase-web.org/documents/SERJ/SERJ11(2)_Ramirez.pdf]

Raykov, T. (1997). Estimation of composite reliability for congeneric measures. Applied Psychological Measurement, 21(2), 173-184.

Reyes, M. R., Brackett, M. A., Rivers, S. E., White, M., \& Salovey, P. (2012). Classroom emotional climate, student engagement, and academic achievement. Journal of Educational Psychology, 104(3), 700-712.

[Online: https://doi.org/10.1037/a0027268] 
Schau, C. (2003, August). Students' attitudes: The "other" important outcome in statistics education. Paper presented at the Joint Statistical Meetings, San Francisco, CA. [Online: http://www.statlit.org/pdf/2003SchauASA.pdf]

Schau, C., Stevens, J., Dauphinee, T. L., \& Vecchio, A. D. (1995). The development and validation of the survey of attitudes toward statistics. Educational and Psychological Measurement, 55(5), 868-875. [Online: https://doi.org/10.1177/0013164495055005022]

Schumacker, R. E., \& Lomax, R. G. (2004). A beginner's guide to structural equation modeling. Lawrence Erlbaum Associates.

Sesé, A., Jiménez, R., Montaño, J. J., \& Palmer, A. (2015). Can attitudes toward statistics and statistics anxiety explain students' "performance". Revista de Psicodidáctica, 20(2), 285-304.

[Online: https://doi.org/10.1387/RevPsicodidact.13080]

Stanisavljevic, D., Trajkovic, G., Marinkovic, J., Bukumiric, Z., Cirkovic, A., \& Milic, N. (2014). Assessing attitudes towards statistics among medical students: Psychometric properties of the Serbian version of the survey of attitudes towards statistics (SATS). PLoS ONE, 9(11). [Online: https://doi.org/10.1371/journal.pone.0112567]

Vanhoof, S., Kuppens, S., Castro Sotos, A. E., Verschaffel, L., \& Onghena, P. (2011). Measuring statistics attitudes: Structure of the Survey of Attitudes Toward Statistics (SATS-36). Statistics Education Research Journal, 10(1), 35-51.

[Online: http://iase-web.org/documents/SERJ/SERJ10(1)_Vanhoof.pdf]

Veiga, F. H., Reeve, J., Wentzel, K., \& Robu, V. (2014). Assessing students' engagement: A review of instruments with psychometric qualities. Envolvimento Dos Alunos Na Escola: Perspetivas Internacionais Da Psicologia E Educação/Students' Engagement in School: International Perspectives of Psychology and Education (pp. 38-57).

[Onlne: http://repositorio.ul.pt/handle/10451/18036]

KONSTANTINOS LAVIDAS

University of Patras

Department of Educational Sciences \& Early Childhood Education 26500, Rio, Patras, Greece 


\section{APPENDIX}

Table 6. Standardized direct, indirect and total effects of model

\begin{tabular}{|c|c|c|c|c|c|c|c|}
\hline & $R^{2}$ & Effect & $\begin{array}{c}\text { Perceived } \\
\text { Competence at } \\
\text { Mathematics }\end{array}$ & Engagement & $\begin{array}{c}\text { Affect \& } \\
\text { Cognitive } \\
\text { Competence }\end{array}$ & Value & Difficulty \\
\hline \multicolumn{8}{|c|}{ Dependent construct } \\
\hline \multirow[t]{3}{*}{ Final Grade } & .432 & Direct & 467 & .376 & --- & --- & --- \\
\hline & & Indirect & .078 & --- & .099 & --- & --- \\
\hline & & Total & .545 & .376 & .099 & --- & --- \\
\hline \multirow[t]{3}{*}{ Engagement } & .069 & Direct & --- & --- & .263 & --- & --- \\
\hline & & Indirect & .208 & --- & ---- & --- & --- \\
\hline & & Total & .208 & --- & .263 & --- & --- \\
\hline \multicolumn{8}{|l|}{$\begin{array}{l}\text { Affect \& } \\
\text { Cognitive }\end{array}$} \\
\hline \multirow[t]{3}{*}{ Competence } & .626 & Direct & .791 & --- & & & \\
\hline & & Indirect & --- & --- & & & \\
\hline & & Total & .791 & --- & & & \\
\hline \multirow[t]{3}{*}{ Value } & .175 & Direct & .418 & --- & & & \\
\hline & & Indirect & --- & --- & & & \\
\hline & & Total & .418 & --- & & & \\
\hline \multirow[t]{3}{*}{ Difficulty } & .191 & Direct & .437 & --- & & & \\
\hline & & Indirect & --- & --- & & & \\
\hline & & Total & .437 & --- & & & \\
\hline
\end{tabular}


Table 7. Regression weights and standardized weights of model

\begin{tabular}{|c|c|c|c|c|c|}
\hline & & & $\begin{array}{c}\text { Regression, } \\
\text { (Standardized) } \\
\text { Weights }\end{array}$ & S.E. & C.R.* \\
\hline $\begin{array}{l}\text { Perceived Competence } \\
\text { at Mathematics }\end{array}$ & $\rightarrow$ & Final Grade & $.415(.467)$ & .059 & 7.031 \\
\hline Engagement & $\rightarrow$ & Final Grade & $.511(.376)$ & .122 & 4.175 \\
\hline Affect_Cognitive & $\rightarrow$ & Engagement & $.240(.263)$ & .074 & 3.250 \\
\hline $\begin{array}{l}\text { Perceived Competence } \\
\text { at Mathematics }\end{array}$ & $\rightarrow$ & Affect_Cognitive & $.567(.791)$ & .047 & 12.126 \\
\hline $\begin{array}{l}\text { Perceived Competence } \\
\text { at Mathematics }\end{array}$ & $\rightarrow$ & Difficulty & $.178(.437)$ & .036 & 4.886 \\
\hline $\begin{array}{l}\text { Perceived Competence } \\
\text { at Mathematics }\end{array}$ & $\rightarrow$ & Value & $.245(.418)$ & .046 & 5.269 \\
\hline $\begin{array}{l}\text { Perceived Competence } \\
\text { at Mathematics }\end{array}$ & $\rightarrow$ & PerCM_l & $1.000(.945)$ & & \\
\hline $\begin{array}{l}\text { Perceived Competence } \\
\text { at Mathematics }\end{array}$ & $\rightarrow$ & PerCM $\_2$ & $.924(.969)$ & .038 & 24.133 \\
\hline Engagement & $\rightarrow$ & Engag_1 & $1.000(.957)$ & & \\
\hline Engagement & $\rightarrow$ & Engag_2 & $.698(.656)$ & .133 & 5.262 \\
\hline Affect_Cognitive & $\rightarrow$ & $P C 1$ & $1(.873)$ & & \\
\hline Affect_Cognitive & $\rightarrow$ & $P C 2$ & $1.142(.943)$ & .061 & 18.701 \\
\hline Affect_Cognitive & $\rightarrow$ & $P \_A l$ & $1.033(.917)$ & .059 & 17.555 \\
\hline Affect_Cognitive & $\rightarrow$ & $P_{-} A 2$ & $1.165(.843)$ & .079 & 14.766 \\
\hline Difficulty & $\rightarrow$ & $P_{-} D 1$ & $1.000(.792)$ & & \\
\hline Difficulty & $\rightarrow$ & $P_{-} D 2$ & $.934(.743)$ & .123 & 7.576 \\
\hline Value & $\rightarrow$ & $P_{-} V l$ & $.850(.735)$ & .077 & 11.098 \\
\hline Value & $\rightarrow$ & $P_{-} V 2$ & $1.000(.874)$ & & \\
\hline Value & $\rightarrow$ & $P_{-} V 3$ & $1.236(.921)$ & .085 & 14.615 \\
\hline Final Grade & $\rightarrow$ & Stat_Mark_l & $.534(.653)$ & .076 & 7.031 \\
\hline Final Grade & $\rightarrow$ & Stat_Mark_2 & $1.000(.982)$ & & \\
\hline
\end{tabular}

${ }^{*}$ C.R. $=$ Weight $/$ S.E. 